\title{
Inflammatory Bowel Disease: An Interview with Dr. John Marshall
}

\author{
Sadaf Arbab-Tafti, BHSc ${ }^{1}$ Joseph Di Michele, BHSc ${ }^{1}$ \\ ${ }^{1}$ Faculty of Medicine, University of Ottawa
}

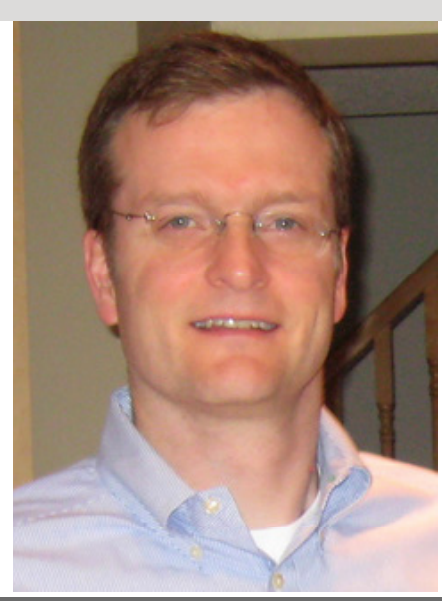

A BSTRACT

Dr. John Marshall is a Professor of Medicine, a Full Member of the Farncombe Family Digestive Health Research Institute, and Head of Clinical Research for the Division of Gastroenterology at McMaster University. He is also Chief of Service for Gastroenterology at Hamilton Health Sciences. Dr. Marshall's clinical and research interests include Inflammatory Bowel Disease (IBD), a group of chronic disorders that cause prolonged inflammation of the gastrointestinal tract. We were able to speak with Dr. Marshall about his clinical and research experiences with IBD and his advice for interested trainees who want to pursue a career in academic medicine.

\section{RÉSUMÉ}

Dr. John Marshall est un professeur de médecine, un membre à temps-plein du Farncombe Family Digestive Health Research Institute, et Chef de recherche clinique pour le département de gastoentérologie à l'Université McMaster. II est aussi chef de service de gastroentérologie à Hamilton Health Sciences. Les intérêts cliniques et de recherche du Dr. Marshall incluent les maladies inflammatoires chroniques de l'intestin ( $\mathrm{MICl}$ ), un groupe de maladies chroniques causant une inflammation prolongée du tractus gastrointestinal. Nous avons eu la chance de discuter avec Dr. Marshall au sujet de ses experiences cliniques et de recherche avec les $\mathrm{MICl}$, ainsi que son avis aux étudiants intéressés à poursuivre une carrière en médecine académique.

Tell us a bit about yourself, your background in health care, and your clinical and research interests.

I am an adult Gastroenterologist at McMaster University. Right now I wear a few different hats. On the university side, I am a Professor of Medicine, so I am involved in teaching, research and all things that universities do. On the hospital side, I am the Chief of Service for Gastroenterology at Hamilton Health Sciences. In terms of my background, I went to medical school at Queen's University in Kingston and actually did an undergraduate degree in Russian Studies, also at Queen's. I did just enough science to get into medical school. After medical school I came to Hamilton, which is where I have stayed since. I did my internship, residency, and fellowship in Gastroenterology here. I then did a Master's degree in Health Research Methodology (HRM) with the Department of Clinical Epidemiology and Biostatistics. In terms of my clinical interests, I still see all forms of gastroenterology, so I haven't limited my practice, but most of what I see is Inflammatory Bowel Disease (IBD). I see more IBD than most of my colleagues here and I enjoy that. In terms of research interests, I have done many different things over the years including work in Irritable Bowel Syndrome, particularly post-infectious Irritable Bowel Syndrome, but also more recently related to IBD. I have

Keywords: Inflammatory Bowel Disease; Gastroenterology; Crohn's Disease; Ulcerative Colitis also been involved in gastrointestinal bleeding, endoscopy and health economics, so I have seen lots of variety over the years.

How did you initially become interested and involved in Inflammatory Bowel Disease research?

I think there is lots of reasons people, including me, get interested in IBD. I think one of the pleasures of dealing with patients with IBD is that these are some of the patients in gastroenterology clinics that we get to know for many years. I finished my fellowship training in 1997, eighteen years ago, so there are people I have seen continuously for eighteen years. I get to know their lives. I get to see them go through different stages. One of the things about IBD which is challenging for patients but really, I think, rewarding for those of us who look after them, is that they tend to come to us young. We see them go through all significant stages of life, including going to school, getting married, having children and starting careers. If they get good care and if they do well you can really see them succeed through all these stages and I think you can see the impact of good care on people's lives much more acutely. It is great to get to know people through all these stages. These are young people so they will probably still be in my practice when I retire. The other reason to get interested in Crohn's and colitis is who you are exposed to in terms 
of colleagues and mentors. I did a lot work as a resident with Dr. Jan Irvine who was on Faculty here at the time and also Dr. Ken Croitoru, who both have interests in IBD and I think working with them drew me to the area and inspired me to some extent. I think it is the condition itself that is interesting but also the people you meet along the way.

\section{Tell us about your past/current Inflammatory Bowel Disease} research projects.

When I did my Master's degree for the HRM program, I did a thesis project. That thesis was comparing ileoscopy with radiologic studies, small bowel meal with pneumocolon, for investigation of terminal ileal Crohn's disease [1]. We looked at the accuracy of each test for detecting disease relative to a gold standard expert consensus panel. That was a big project I did all by myself, 120 patients. It got published and obviously that was rewarding at the time. I have done lots of different studies over the years since. Early in my career I had a great interest in health economics. I did some work looking at cost-effectiveness of different therapies for IBD, specifically around biologic therapy for Crohn's disease [2]. When infliximab was first introduced, there was a lot of debate around its cost relative to its benefit and I actually did one of the big cost-effectiveness analyses for a government agency that was looking at the issue. That was hard work but also very rewarding and it is something that has still been cited many years later.

More recently, I have been doing some work looking at Nurse Practitioners. We are one of the few IBD centers in Canada to have a Nurse Practitioner with a practice focused in IBD, so we have been doing some work looking at the impact of that Nurse Practitioner on the care of patients and their health outcomes. Another thing I have been involved with is looking at the experience of some of our pediatric patients. We are one of the few centres in Canada that have both pediatric and adult IBD care under the same roof, so we have used this as an opportunity to look at the experience of some of the children with IBD transitioning to adult care. Plus, we, like many other centres, participate in multicentre trials looking at therapy for Crohn's and colitis. For those trials, we may be just one recruiting centre of many, but it is both interesting academically and good service to our patients to make sure they have access to new and emerging therapies through participation in clinical trials. Finally, we are also participating as a recruiting centre for a large project with Crohn's and Colitis Canada, the GEM project, looking for some of the early causes of Crohn's and colitis in people who are at risk because of a family history of IBD. Those are some of the projects I have been involved with and still have going on.
Can you tell us a bit about Inflammatory Bowel Disease and its current management? What is the current state of health in patients with Inflammatory Bowel Disease? How could the current state of health in these patients be improved?

When we talk about the term IBD we are referring to two different but similar conditions that we call Crohn's disease and ulcerative colitis. Ulcerative colitis is inflammation of the colon that always affects the rectum but spreads proximally to a varying degree in different people, sometimes as far as the cecum, but it only affects the colon and does not spread to other parts of the gastrointestinal tract. Crohn's disease, however, is a "gum-tobum" disorder that can affect any segment of the gastrointestinal tract, most often the terminal ileum, the last section of the small bowel, but you can have disease anywhere in the digestive system. In Crohn's disease, the inflammation can go deeper than the wall of the gut and even burrow through it to form tunnels called fistulas that can lead to complications like abscesses. Crohn's disease is also a little more prone to scarring and fibrosis that can lead to bowel obstructions. These two conditions are very similar in that they are both inflammations of the lining of the gut but they have some differences. A lot of people would argue that Crohn's disease is probably not just one condition but many conditions that we lump together as Crohn's disease since it is very heterogeneous and each patient with Crohn's disease tends to have a very different story.

Crohn's and colitis are not just short-term problems; they are life-long conditions. There is no cure for either of these, so once people are diagnosed, they will carry that diagnosis for the rest of their lives. I think a change in our approach to IBD patients over the last ten years has been to look less just in terms of how people feel today but really looking at how well their disease is controlled over the long run, because our eye is much more on the horizon in making sure that they do well in twenty or thirty years, not just today. I think that thinking has changed our approach to Crohn's and colitis and remember, as I said before, it affects young people at a very important stage of life, so good control of disease early could have big effects on people's life experiences. I have to say I do not think I am very old yet but in my career I have seen a huge change in what people can expect from a diagnosis of Crohn's and colitis. Twenty years ago we were really treating people largely with steroids and a lot of surgery with a lot of complications from both treatment modalities. I think a lot of the problems we were dealing with back then were the complications rather than the disease itself. Now we have a lot more treatments available and I think we have a better understanding of the importance of early control of inflammation and so the expectation of someone diagnosed with Crohn's or coli- 
tis in 2015 is much different from someone who was diagnosed twenty years ago. I think if we do things right almost all of these patients should expect a normal quality of life and that is a real switch in how people with Crohn's or colitis do.

When treating, one thing that we do very carefully now is try to risk stratify people. We look both at how active their disease is but also look for any signs that they could face a benign or more aggressive course of disease over their life. That said, we could treat people with similar symptoms very differently depending on whether we think they are high or low risk. In a high risk person, even if they do not feel that unwell or are not that sick, we might treat very aggressively because we know that control of their disease early can have downstream benefits. In someone who has a very benign form of disease, we may be happy just to give short term treatment and not necessarily commit to long term therapy. So we look both at how active the disease is and how high or low risk the patient is.

For short-term treatment, sometimes we still need to use corticosteroids but we are trying to use less and less over time because we know they have short- and long-term side effects. We have a class of therapies referred to as immunomodulators or immunosuppressants such as methotrexate and azathioprine. There has been a little debate around azathioprine in the last few years around safety; we know it does have some potential side effects, including increased risks of lymphoproliferative disorders in young patients, so these days we are having very careful discussions about risks and benefits with patients that we start on these therapies. No question, the biggest change in our management has been the arrival of biologic therapies. We now have three anti-TNF monoclonal antibodies available for treatment of Crohn's or colitis and those are adalimumab, infliximab, and golimumab. Just recently approved in Canada is another biologic called vedolizumab, which has a different mechanism of action by interacting with leukocyte trafficking. We have a lot more options than we used to, and these drugs have really been the ones that have changed the outlook and expectations for people with Crohn's or colitis. They are expensive but they are also very effective both in the short and long run. When we get back to thinking about the costs and the benefits we can make a strong argument that the benefits really do outweigh the costs with biologics. Surgery is sometimes necessary, but I think the proportion of patients going into surgery these days is much lower than what it was twenty years ago, and I think that is because we have better medical therapy. However, there are situations where surgery is still the best option, but again, it is less common than it used to be.
What research work do you think is needed in Inflammatory Bowel Disease? What direction would you like to see Canada take with regards to management of this chronic disease?

I think there is lots of research still to be done in Crohn's and colitis, and I think we are in a very exciting era where we have new technologies that may give us new answers about understanding what causes Crohn's and colitis and obviously how to treat it better. One thing we really need more information about is our predictive tools. We need better ways of risk stratifying patients and dividing people into high and low-risk phenotypes so we can invest our most expensive and effective therapies in the people who would really stand to benefit the most. The predictors we have right now are a little blunt. They are not that accurate, so we need better tools to do that. There is also a lot of work being done looking at genetics, serologic markers and aspects of the gut microbiome, as well as predictors of response to therapy. There is lots of animal work showing that the microbes in the gut are part of the inflammation that drives Crohn's and colitis, but we are just beginning to understand whether we could modify the microbiome in a way to help control the disease, and I think that is a frontier which will be the topic of a lot of discussion and activity in the next couple of decades as technology is getting better to try to profile the microbiome. Medical informatics is a huge field that needs more manpower because it's a new area of specialty as we are getting more, better tools and methodology to crunch all the data that are produced from analyzing the microbiome, the virome of the stool and the proteome of the blood as well. There is all sorts of technology that is just emerging that hopefully will give us some of these answers.

What advice would you give to students who want to pursue this kind of career? Can you describe what your weekly schedule is like? How do you balance your family and work life?

I think one of the reasons I went into gastroenterology is because I never met an unhappy gastroenterologist who regretted their career decision and I still have yet to meet one. Gastroenterology is a great field of clinical activity partly because we deal with a whole range of people in age and acuity of illness. We deal with very sick people, for example with bad IBD, and we also deal with perfectly healthy people having screening procedures for cancer detection. We deal with both younger and older people so there is a lot of variety there, plus our weeks are varied. We have days when we are seeing patients in the clinic, days when we are doing procedures in the endoscopy suite, and days when we are managing patients in the hospital. There is a lot of variety in gastroenterology that keeps people very engaged and seems to sustain people's enjoyment of their career over time. There 
is no question it is hard work if people want to do both clinical gastroenterology and pursue an academic career in teaching and research; it is a lot of balls that you need to keep in the air, but, like anything in life, if you really enjoy what you are doing and find it rewarding, then the hard work doesn't seem as onerous and there are lots of rewards in terms of job satisfaction. I think anyone starting a career in medicine needs to find what they really enjoy and follow that. You cannot be too focused on the short-term goals such as getting the right job this year; you have to really look at the long-run. If you enjoy what you do and if you work hard at it the opportunities will present themselves. It is a bit of a challenging time in Canada right now for careers in gastroenterology. The number of people being trained has increased so there has been more competition for jobs, but my observation is that good people always find the right job eventually and there needs to be a bit of patience.

It will always be a challenge in a busy career and in any branch of medicine, trying to balance personal life versus professional life. Professional life in medicine can be all-consuming and I think you just need to find ways to block off time for yourself. In an academic career, there are times when you can do some of your work from home or after hours so you could move some of it around to create flexibility. I think even though my work has been pretty busy, I have still found ways to spend occasional days with my kids and I still made their Christmas concerts and watched their sports games, so it can be done. I think you have to recognize that you do not have to say yes to every opportunity that comes your way. That is very difficult when you are starting out in your career because medicine is full of exciting opportunities and places to go, meetings to attend, patients to see and the hardest word anyone ever learns in medicine is to say "no." Sometimes you have to say no and the same opportunities will present themselves down the road, but don't be dissuaded, it's a great career.

\section{ACKNOWLEDGEMENTS}

The authors would like to thank Dr. John Marshall for graciously taking the time to answer all of our questions and for approving the final version of this article. For further information about Dr. Marshall and his research projects, please visit his research group's website at http://farncombe.mcmaster.ca.

\section{REFERENCES}

1. Marshall JK, Cawdron R, Zealley I, Riddell RH, Somers S, Irvine EJ. Prospective comparison of small bowel meal with pneumocolon versus ileoscopy for diagnosis of ileal Crohn's disease. Am J Gastroenterol 2004;99:1321-9.

2. Marshall JK, Blackhouse G, Goeree R, Brazier N, Irvine E, Faulkner L, Dipchand C, O'Brien B. Infliximab for the treatment of Crohn's disease: a systematic review and cost-utility analysis. Ottawa: Canadian Coordinating Office for Health Technology Assessment; 2002. Technology Report no 24. 